\title{
Acute kidney injury incidence and acute renal replacement modality in intensive care unit patients in Indonesia: A result from Southeast Asia-Acute Kidney Injury Study
}

Jonny Jonny

Gatot Soebroto Central Army Presidential Hospital

Moch Hasyim

Gatot Soebroto Central Army Presidential History

Vedora Angelia

Gatot Soebroto Central Army Presidential Hospital

Ayu Nursantisuryani Jahya

Gatot Soebroto Central Army Presidential Hospital

Lydia Permata Hilman

Gatot Soebroto Central Army Presidential Hospital

Venna Febrian Kusumaningrum

Gatot Soebroto Central Army Presidential Hospital

Nattachai Srisawat ( $\nabla$ drnattachai@yahoo.com )

Chulalongkorn University Faculty of Medicine https://orcid.org/0000-0002-8544-8132

Research article

Keywords: Acute kidney injury, intensive care unit, incidence, renal replacement therapy

Posted Date: February 26th, 2020

DOI: https://doi.org/10.21203/rs.2.24585/v1

License: (c) (1) This work is licensed under a Creative Commons Attribution 4.0 International License.

Read Full License

Version of Record: A version of this preprint was published at BMC Nephrology on May 20th, 2020. See the published version at https://doi.org/10.1186/s12882-020-01849-y. 


\section{Abstract}

Background : Currently, there is limited data of large databases of acute kidney injury (AKI) epidemiology from Southeast Asia, especially in Indonesia, the biggest countries in. Therefore, we aimed to provide demographic data of intensive care unit (ICU) patients with AKI and the utilization of renal replacement therapy (RRT) in Indonesia.

Methods : We collected demographic and clinical data from 952 ICU patients. Patients were classified into AKI and non-AKI. AKI was classified according to the Kidney Disease Improving Global Outcome (KDIGO) criteria in three stages. We then assess the Acute Physiology and Chronic Health Evaluation (APACHE) II score of AKI and non-AKI patients. RRT modalities were listed down by the number of procedures conducted.

Results : Overall incidence of AKI was $43 \%$, distributed among three stages: $18.5 \%$ stage $1,33 \%$ stage 2 , $48.5 \%$ stage 3. Patients developing AKI need mechanical ventilation more often in comparison with nonAKI. Patients with AKI have an average APACHE score of 16.5, while non-AKI patients have an average score of 9.9. Among AKI patients, $24.6 \%$ requires RRT. The most common RRT modalities were intermittent hemodialysis (69.4\%), followed by slow low efficiency dialysis $(22.1 \%)$, continuous renal replacement therapy (4.2\%), and peritoneal dialysis (1.1\%).

Conclusions: This study showed that AKI is a common problem in Indonesian ICU with containing a high mortality rate. We strongly believe that identification the risk factor of AKI will provide the opportunity to develop the predictability score for AKI prevention and finally improve AKI outcome.

\section{Background}

Acute kidney injury (AKI) is a common problem and often associated with high morbidity and mortality worldwide. The International Society of Nephrology (ISN) truly emphasizes the importance of preventing mortality of untreated AKI in low resource regions by 2025. This notion is emphasized towards poor countries with poor medical access and resources in Africa, Latin America, and Asia. ${ }^{(1)}$ Acute kidney injury occurring in the intensive care unit (ICU) patients complicates and further worsen their clinical condition. Recently, the incidence of AKI varies between $6-70 \%$ among patients treated in the ICU and $57 \%$ of ICU patients tend to develop AKI. ${ }^{(2)}$

On average, $5 \%$ of ICU patients with severe AKI require renal replacement therapy (AKI-RRT). ${ }^{(3)} \mathrm{AKI}$ in ICU patients presents with diverse forms of clinical outcomes such as prolonged ICU stay by 3.5 days, reduced health-related quality of life, a requirement of mechanical ventilation, and detrimental clinical consequences (acid-base disorders, hypervolemia, hyperkalemia, uremia, immune system depression). These variables are highly associated with the current mortality rates of AKI patients ranging from 40$60 \% .(4,5)$ These findings suggested that ICU patients are highly susceptible to AKI and most of the time portends poor prognosis. 
This study aimed to fill in the gap of the minimal amount of AKI epidemiology data in Indonesia. Moreover, we intended to explore the risk factors of AKI and evaluate the incidence of acute RRT-treated in ICU.

\section{Methods}

\section{Patient and data collection}

This study was a prospective observational study in ICU of the Gatot Soebroto Indonesia Central Army Hospital. We collected ICU database for adult patients from January 2017 until December 2018, and further staged the severity of the disease (stage I - III). We enrolled patients aged $>15$ years. Patients with end-stage renal disease (ESRD) on chronic dialysis were excluded (Fig. 1). For patients with multiple admissions, we collected data from only the first admission. The study protocol was reviewed by the institutional review boards (IRB No. B/2212/VIII/2019) and the need for informed consent was waived.

Demographic and clinical data from all patients were collected, such as admission date, gender, age, body mass index (BMI), primary diagnosis at ICU admission, history of comorbid conditions, AKI stages, RRT modes and mechanical ventilation during ICU stay. Severity of the patient's was determined with the Acute Physiology and Chronic Health Evaluation II (APACHE II) and Sequential Organ Failure Assessment (SOFA) scoring system. RRT modes was recorded accordingly per technique, the main-4 techniques are acute peritoneal dialysis (PD), intermittent hemodialysis (IHD), sustained low efficiency dialysis (SLED), and continuous renal replacement therapy (CRRT). We recorded the amount of each technique used most or as an initiation mode throughout the period of January 2017-December 2018 for each patient.

\section{Definition And Classification Of Acute Kidney Injury}

Definition of AKI was determined based on the worst of either creatinine or urine output criteria during hospital stay. Urine output was hourly measured during ICU stay. The cutoffs for AKI were based on the KDIGO criteria as meeting one of the following criteria: an increase serum creatinine of $\geq 0.3 \mathrm{mg} / \mathrm{dL}$ ( $\geq$ $26.4 \mathrm{rmol} / \mathrm{L}$ ) or an increase in creatinine $\geq 50 \%$ (1.5 fold from baseline) in a 48-hour time frame, or reduction in urine output with documented oliguria of $\leq 0.5 \mathrm{~mL} / \mathrm{kg}$ per hour for $\geq 6$ hours. Patients were divided into three groups according to the KDIGO criteria: stage $1-3 .{ }^{(6)}$ When a patient's condition met the aforementioned criteria, the patient was classified as stage $1 \mathrm{AKI}$. In the case of more severe derangement, i.e., a decrease in GFR $\geq 50 \%$ or an increase in creatinine $\geq 100 \%$ ( 2 fold from baseline) in a 48-hour time frame, or a reduction in urine output with documented oliguria of $\leq 0.5 \mathrm{~mL} / \mathrm{kg}$ per hour for $\leq 12$ hours, stage 2 AKI was defined. Stage 3 AKI was defined as follows: a decrease in GFR $\leq 75 \%$ or an increase in creatinine $\geq 200 \%$ ( 3 fold from baseline) in a 48-hour time frame, or a reduction in urine output with documented oliguria of $\leq 0.3 \mathrm{~mL} / \mathrm{kg}$ per hour for $\geq 24$ hours or anuria for $\geq 12$ hours. Serum creatinine $\geq 4.0 \mathrm{mg} / \mathrm{dL}$ with acute increase of $\geq 0.5 \mathrm{mg} / \mathrm{dL}$ was also defined as stage 3 AKI. ${ }^{(7)}$ 


\section{Statistical analysis}

Categorical data were presented as counts and percentages. Continuous data were presented as mean and standard deviation (SD) if normally distributed or median with interquartile range if non-normally distributed. Kaplan-Meier survival curves were also generated for each AKI class. The Chi-square test of independence was used to compare the proportions of different types of patients between patients by AKI status, whereas as ANOVA was used to compare continuous patient characteristics by AKI status.

\section{Results}

Flow chart of the study can be seen in Fig. 1. Among all study participants ( $N=952), 87$ were excluded because 1 patient is admitted with no creatinine data and 86 patients are admitted due to ESRD. From 865 patients, almost half of the patients (43\%) suffer from AKI. In terms of staging, $48.5 \%$ patients suffered from stage III AKI, far higher than the number of patients with AKI stage I, $18.5 \%$, and AKI stage II, $33 \%$.

Among all ICU patients diagnosed with AKI, the average age of those patients was $58( \pm 15)$ years old and $64.6 \%$ were male. Patients primary diagnosis upon ICU admission were most likely due to surgical-related disease, 23.5\% ( $\mathrm{N}=87)$, cardiovascular disease, $19.2 \%(\mathrm{~N}=71)$, and neurologic disease, $15.9 \%(\mathrm{~N}=59)$. Metabolic problems such as hypertension $39.4 \%(\mathrm{~N}=147)$ and diabetes mellitus $38.9 \%(\mathrm{~N}=145)$ happened to be the most common comorbid conditions in AKI patients. Table 1 showed statistically significant difference between AKI patients and non-AKI patients in need of mechanical ventilation, when $49.6 \%$ of AKI patients $(N=185)$ need mechanical ventilation, and only $17.3 \%$ in non-AKI patients $(N=85)$. The severity scoring (APACHE II) was significantly higher in AKI patients (17.1) compared to non-AKI patients (11.2). Non-renal SOFA score was also found to be significantly higher in AKI patients compared to non-AKI patients (5.0 vs 3.0, $p<0.001$ ). (Fig. 2) 
Table 1

Patients characteristics stratifies by AKI status $(\mathrm{N}=865)$

\begin{tabular}{|lllll|}
\hline Characteristics & $\begin{array}{l}\text { Non-AKI } \\
(\mathbf{N}=492)\end{array}$ & $\begin{array}{l}\text { AKI } \\
(\mathbf{n}=373)\end{array}$ & $\begin{array}{l}\text { All } \\
(\mathbf{N}=865)\end{array}$ & P-value \\
\hline Age, years, mean (sd) & $55(15)$ & $58(15)$ & $57(15)$ & 0.008 \\
\hline Male gender, $\mathrm{n}(\%)$ & $297(60.4)$ & $219(58.7)$ & $516(59.7)$ & 0.62 \\
\hline Reimbursement & $(\mathrm{N}=486)$ & $(\mathrm{N}=362)$ & $(\mathrm{N}=848)$ & $0.45^{1}$ \\
\hline - Government officer & $261(53.7)$ & $190(52.5)$ & $451(53.2)$ & \\
\hline - Private health insurance & $0(0.0)$ & $2(0.6)$ & $2(0.2)$ & \\
\hline - Social security system & $211(43.4)$ & $159(43.9)$ & $370(43.6)$ & \\
\hline - Cash/self-pay & $14(2.9)$ & $10(2.8)$ & $24(2.8)$ & \\
\hline - Unknown & $0(0.0)$ & $1(0.3)$ & $1(0.1)$ & \\
\hline BMI, $n$ (\%) & & & & \\
\hline - Underweight & $14(2.8)$ & $16(4.3)$ & $30(3.5)$ & \\
\hline - Normal & $421(85.6)$ & $287(76.9)$ & $708(81.8)$ & \\
\hline - Overweight & $54(11.0)$ & $56(15.0)$ & $110(12.7)$ & \\
\hline - Obese & $3(0.6)$ & $14(3.8)$ & $17(2.0)$ & \\
\hline Primary diagnosis, $\mathrm{n}(\%)$ & $(\mathrm{N}=491)$ & $(\mathrm{N}=370)$ & $(\mathrm{N}=861)$ & \\
\hline - Cardiovascular diseases & $106(21.6)$ & $71(19.2)$ & $177(20.6)$ & \\
\hline - Endocrine Diseases & $11(2.2)$ & $18(4.9)$ & $29(3.4)$ & \\
\hline - Gastrointestinal Diseases & $13(2.6)$ & $18(4.9)$ & $31(3.6)$ & \\
\hline - Hematologic Diseases & $1(0.2)$ & $1(0.3)$ & $2(0.2)$ & \\
\hline - Infectious Diseases & $14(2.9)$ & $36(9.7)$ & $50(5.8)$ & \\
\hline - Neurologic Diseases & $42(8.6)$ & $59(15.9)$ & $101(11.7)$ & \\
\hline - Oncologic Diseases & $13(2.6)$ & $12(3.2)$ & $25(2.9)$ & \\
\hline & & & & \\
\hline
\end{tabular}

BMI: body mass index, DM: diabetes mellitus, CAD: coronary artery disease, CVD: cerebrovascular disease, APACHE II: acute physiologic and chronic health evaluation II, SOFA: sequential organ failure assessment.

TAll these parameters came from the first day of ICU admission.

${ }^{*} \mathrm{P}$ value from Fisher's exact test instead of chi-square 


\begin{tabular}{|c|c|c|c|c|}
\hline Characteristics & $\begin{array}{l}\text { Non-AKI } \\
(\mathrm{N}=492)\end{array}$ & $\begin{array}{l}\text { AKI } \\
(n=373)\end{array}$ & $\begin{array}{l}\text { All } \\
(N=865)\end{array}$ & P-value \\
\hline - Renal Diseases & $9(1.8)$ & $29(7.8)$ & $38(4.4)$ & \\
\hline - Respiratory Diseases & $17(3.5)$ & $36(9.7)$ & $53(6.2)$ & \\
\hline - Rheumatologic Diseases & $0(0.0)$ & $3(0.8)$ & $3(0.3)$ & \\
\hline - Surgical related diseases & $265(54.0)$ & $87(23.5)$ & $352(40.9)$ & \\
\hline \multicolumn{5}{|l|}{ Comorbidity, n (\%) } \\
\hline HT & $210(42.7)$ & $147(39.4)$ & $357(41.3)$ & 0.33 \\
\hline DM & $114(23.2)$ & $145(38.9)$ & $259(29.9)$ & $<0.001$ \\
\hline CKD & $3(0.6)$ & $43(11.5)$ & $46(5.3)$ & $<0.001^{1}$ \\
\hline Cerebrovascular & $4(0.8)$ & $11(2.9)$ & $15(1.7)$ & 0.017 \\
\hline Malignancy & $24(4.9)$ & $18(4.8)$ & $42(4.9)$ & 0.97 \\
\hline CAD & $52(10.6)$ & $19(5.1)$ & $71(8.2)$ & 0.004 \\
\hline APACHE-II score, mean (sd) & $9.9(4.4)$ & $16.5(7.3)$ & $12.7(6.7)$ & $<0.001$ \\
\hline Non-renal SOFA score, mean (sd) & $3.0(1.6)$ & $5.0(2.5)$ & $3.9(2.3)$ & $<0.001$ \\
\hline Vasopressors, n (\%) & $4(0.8)$ & $41(11.0)$ & $45(5.2)$ & $<0.001$ \\
\hline Mechanical ventilation, n (\%) & $85(17.3)$ & $185(49.6)$ & $270(31.2)$ & $<0.001$ \\
\hline \multicolumn{5}{|c|}{$\begin{array}{l}\text { BMI: body mass index, DM: diabetes mellitus, CAD: coronary artery disease, CVD: cerebrovascular } \\
\text { disease, APACHE II: acute physiologic and chronic health evaluation II, SOFA: sequential organ failure } \\
\text { assessment. }\end{array}$} \\
\hline \multicolumn{5}{|c|}{ †All these parameters came from the first day of ICU admission. } \\
\hline${ }^{*} \mathrm{P}$ value from Fisher's exact test & chi-squa & & & \\
\hline
\end{tabular}

Table 2 further elaborates the risk factors for developing AKI. it shows that patients who developed AKI during ICU stay are 4.53 times more likely to be admitted to the ICU with renal disease as their primary diagnosis, and has 1.14 times more likely to have higher APACHE II compare to those without AKI. 
Table 2

Risk factors for AKI development using logistic regression analysis.

\begin{tabular}{|c|c|c|c|c|}
\hline - Characteristics & $\begin{array}{l}\text { Unadjusted OR (95\% } \\
\mathrm{Cl)}\end{array}$ & $\begin{array}{l}\mathrm{P} \text { - } \\
\text { value }\end{array}$ & $\begin{array}{l}\text { Adjusted OR } \\
(95 \% \mathrm{Cl})\end{array}$ & $\begin{array}{l}\mathrm{P} \text { - } \\
\text { value }\end{array}$ \\
\hline Age, 10-year increment & $\begin{array}{l}1.11 \\
(1.02,1.22)\end{array}$ & 0.019 & $\begin{array}{l}0.90 \\
(0.80,1.02)\end{array}$ & 0.11 \\
\hline Male gender, n (\%) & $\begin{array}{l}0.93 \\
(0.70,1.22)\end{array}$ & 0.598 & & \\
\hline \multicolumn{5}{|l|}{ Reimbursement, $\mathrm{N}=834$} \\
\hline - Government officer & $\begin{array}{l}0.98 \\
(0.74,1.29)\end{array}$ & 0.869 & & \\
\hline - Social security system & Reference & & & \\
\hline $\begin{array}{l}\text { - Private health insurance /Cash/self- } \\
\text { pay }\end{array}$ & $\begin{array}{l}1.18 \\
(0.53,2.61)\end{array}$ & 0.690 & & \\
\hline \multicolumn{5}{|l|}{ BMI } \\
\hline - Underweight & $\begin{array}{l}1.60 \\
(0.76,3.36)\end{array}$ & 0.217 & $\begin{array}{l}1.18 \\
(0.48,2.91)\end{array}$ & 0.73 \\
\hline - Normal & Reference & & Reference & \\
\hline - Overweight / obese & $\begin{array}{l}1.67 \\
(1.14,2.47)\end{array}$ & 0.009 & $\begin{array}{l}1.55 \\
(0.97,2.49)\end{array}$ & 0.07 \\
\hline \multicolumn{5}{|l|}{ Primary diagnosis ${ }^{\star *}, \mathrm{~N}=846$} \\
\hline - Cardiovascular diseases & $\begin{array}{l}0.90 \\
(0.64,1.26)\end{array}$ & 0.528 & & \\
\hline - Endocrine Diseases & $2.31(1.08,4.95)$ & 0.032 & $\begin{array}{l}0.97(0.38 \\
2.49)\end{array}$ & 0.95 \\
\hline - Gastrointestinal Diseases & $1.94(0.94,4.02)$ & 0.073 & $\begin{array}{l}1.20(0.49 \\
2.99)\end{array}$ & 0.69 \\
\hline - Hematologic Diseases & $1.37(0.09,21.99)$ & 0.824 & & \\
\hline - Infectious Diseases & $3.81(2.02,7.17)$ & $<.001$ & $\begin{array}{l}1.15(0.51 \\
2.57)\end{array}$ & 0.74 \\
\hline
\end{tabular}

†All these parameters came from the first day of ICU admission

łexclude 15 patients who had AKI as the primary diagnosis for ICU admission

BMI: body mass index, DM: diabetes mellitus, CAD: coronary artery disease, CVD: cerebrovascular disease, APACHE II: acute physiologic and chronic health evaluation I, SOFA: sequential organ failure assessment. NA: not included in the multivariable model even if $* P<0.20$ because it didn't have enough data 


\begin{tabular}{|c|c|c|c|c|}
\hline - Characteristics & $\begin{array}{l}\text { Unadjusted OR (95\% } \\
\mathrm{Cl})\end{array}$ & $\begin{array}{l}\mathrm{P}- \\
\text { value }\end{array}$ & $\begin{array}{l}\text { Adjusted OR } \\
(95 \% \mathrm{Cl})\end{array}$ & $\begin{array}{l}\mathrm{P} \text { - } \\
\text { value }\end{array}$ \\
\hline - Neurologic Diseases & $2.06(1.35,3.15)$ & 0.001 & $\begin{array}{l}0.97(0.53 \\
1.77)\end{array}$ & 0.92 \\
\hline - Oncologic Diseases & $1.27(0.57,2.83)$ & 0.552 & & \\
\hline - Renal Diseases & $3.87(1.61,9.31)$ & 0.003 & $\begin{array}{l}4.53(1.67 \\
12.33)\end{array}$ & 0.003 \\
\hline - Respiratory Diseases & $2.92(1.61,5.32)$ & $<.001$ & $\begin{array}{l}1.53(0.72 \\
3.25)\end{array}$ & 0.27 \\
\hline - Surgical related diseases & $0.27(0.20,0.37)$ & $<.001$ & $\begin{array}{l}0.60(0.39 \\
0.93)\end{array}$ & 0.021 \\
\hline \multicolumn{5}{|l|}{ Comorbidity $\star \star \star ~$} \\
\hline HT & $0.88(0.66,1.16)$ & 0.348 & & \\
\hline DM & $2.05(1.52,2.77)$ & $<.001$ & $\begin{array}{l}1.08 \\
(0.73,1.61)\end{array}$ & 0.71 \\
\hline Cerebrovascular & $3.83(1.21,12.13)$ & 0.022 & $\begin{array}{l}1.55 \\
(0.39,6.17)\end{array}$ & 0.53 \\
\hline Malignancy & $1.02(0.55,1.91)$ & 0.946 & & \\
\hline CAD & $0.47(0.27,0.81)$ & 0.006 & $\begin{array}{l}0.50 \\
(0.26,0.98)\end{array}$ & 0.042 \\
\hline APACHE-II score & $1.21(1.17,1.25)$ & $\begin{array}{l}< \\
0.001\end{array}$ & $1.14(1.09,1.20)$ & $\begin{array}{l}<.001 \\
0.00\end{array}$ \\
\hline Non-renal SOFA score & $\begin{array}{l}1.62 \\
(1.49,1.76)\end{array}$ & $<.001$ & $\begin{array}{l}1.14 \\
(1.00,1.31)\end{array}$ & 0.050 \\
\hline Vasopressors & $\begin{array}{l}13.08 \\
(4.61,37.17)\end{array}$ & $<.001$ & $\begin{array}{l}2.99 \\
(0.93,9.62)\end{array}$ & 0.067 \\
\hline Mechanical ventilation & $\begin{array}{l}4.76 \\
(3.49,6.51)\end{array}$ & $<.001$ & $\begin{array}{l}1.29 \\
(0.80,2.08)\end{array}$ & 0.30 \\
\hline \multicolumn{5}{|c|}{ †All these parameters came from the first day of ICU admission } \\
\hline \multicolumn{5}{|c|}{ fexclude 15 patients who had AKI as the primary diagnosis for ICU admission } \\
\hline \multicolumn{5}{|c|}{$\begin{array}{l}\text { BMI: body mass index, DM: diabetes mellitus, CAD: coronary artery disease, CVD: cerebrovascular } \\
\text { disease, APACHE II: acute physiologic and chronic health evaluation I, SOFA: sequential organ failure } \\
\text { assessment. NA: not included in the multivariable model even if * } \mathrm{P}<0.20 \text { because it didn't have } \\
\text { enough data }\end{array}$} \\
\hline
\end{tabular}

Among those patients who received RRT support, IHD is the most common procedure used as the initial mode of RRT in ICU (66 procedures, 71.7\%), followed by SLED (21 procedures, 22.8\%), then CRRT (4 
procedures, $4.34 \%$ ) and acute PD (1 procedure, 1.08\%). (Table 3)

Table 3

Mode of RRT (initiation mode if there were many most used modes with same duration)

\begin{tabular}{|ll|}
\hline Mode of RRT & N (\%) \\
\hline IHD & $66(71.7)$ \\
\hline CRRT & $4(4.34)$ \\
\hline PD & $1(1.08)$ \\
\hline SLED & $21(22,8)$ \\
\hline $\begin{array}{l}\text { IHD: intermittent hemodialysis, CRRT: continuous renal replacement therapy, PD: peritoneal dialysis, } \\
\text { SLED; sustained low efficiency dialysis }\end{array}$ \\
\hline
\end{tabular}

Table 4 summarized the severity in AKI patients. The number of patients who were grouped into severe AKI reached $48.5 \%$ of the populations with $\mathrm{AKI}(\mathrm{N}=181)$. Based on multivariate analysis using logistic regression, patients who developed severe AKI are 2.47 times more likely to be male, 9.47 times more likely to have CKD and 3.43 times more likely to have malignancy as their comorbidities. They also more likely to have higher APACHE II score (OR: 1.07; 95\% Cl: 1.01-1.13), compare to less severe AKI patients. Patients with severe AKI were also 5.41 times more likely to require vasopressors during their ICU stay. 
Table 4

Patients characteristics and risk factors for severity of AKI using logistic regression $(N=226)$

\section{Characteristics}

\section{Severity of AKI, $n(\%)$}

$\begin{array}{llllll}\text { Non-severe } & \text { Severe } & \text { Unadjusted } & \text { P- } & \text { Adjusted } & \text { P- } \\ (\mathrm{N}=192) & (\mathrm{N}=181) & \text { OR }(95 \% \mathrm{Cl}) & \text { value } & \text { OR }(95 \% & \text { value } \\ & & & & \mathrm{Cl}) & \end{array}$

Age, 10-year increment ${ }^{1} \quad 59$ (14)

$57(15)$

0.93

$(0.81,1.07)$

Male gender, n (\%)

$98(51.0)$

121

(66.9)
1.93

$(1.27,2.94)$
0.284

0.002

2.47

(1.48,

4.12)
0.001

Reimbursement, $\mathrm{N}=361$

- Government officer

96 (51.3) $94(54.0)$

1.04

0.85

$(0.68,1.59)$

- Social security system

$82(43.9)$

77 (44.3) Reference

- Private health

9 (4.8)

$3(1.7)$

0.35

$(0.09,1.36)$

0.13

insurance/Cash/self-

pay

BMI

- Underweight

$6(3.1)$

$10(5.5)$

2.32

$(0.82,6.56)$

0.11

2.26

$(0.7,7.32)$

0.18

- Normal

$167(87.0)$

120

(66.3)

Reference

Reference

- Overweight / obese

19

(9.9)
51

(28.2)
3.74

$(2.10,6.65)$
$<2.26$

$0.001 \quad(0.7,7.32)$

0.18

Primary diagnosis, $\mathrm{N}=$ 370

- Cardiovascular

diseases

- Endocrine Diseases
$40(21.1)$

$12(6.3)$
31 (17.2)

6 (3.3)
0.78

$(0.46,1.31)$

0.51

$(0.19,1.39)$
0.35

0.19
0.41(0.12, 1.44)

tValue in cell is mean (sd) instead of $n(\%)$

$\ddagger$ All these parameters came from the first day of ICU admission

BMI: body mass index, DM: diabetes mellitus, CAD: coronary artery disease, CVD: cerebrovascular disease, APACHE II: acute physiologic and chronic health evaluation II, SOFA: sequential organ failure assessment

NA: not included in the multivariable model even if $P<0.20$ because it didn't have enough data 


$\begin{array}{llllll}\text { Non-severe } & \text { Severe } & \text { Unadjusted } & \text { P- } & \text { Adjusted } & \text { P- } \\ (\mathrm{N}=192) & (\mathrm{N}=181) & \text { OR }(95 \% \mathrm{Cl}) & \text { value } & \text { OR }(95 \% & \text { value } \\ & & & & \mathrm{Cl}) & \end{array}$

- Gastrointestinal

Diseases

- Hematologic Diseases $\quad 0(0.0)$

- Infectious Diseases $13(6.8)$

$27(14.2)$

- Neurologic Diseases

- Oncologic Diseases

Renal Diseases

-Respiratory Diseases

- Rheumatologic

Diseases

- Surgical related diseases

$11(5.8)$

$6(3.2)$

$8(4.2)$

$16(8.4)$

$1(0.5)$

$56(29.5)$
$7(3.9)$

$1(0.6)$

$23(12.8)$

$(0.98,4.07)$

$(0.25,1.74)$

NA

\subsection{1}

$(0.75,2.28)$

$32(17.8)$

$6(3.3)$

1.06

$(0.33,3.34)$

$21(11.7)$

3.00

$(1.30,6.97)$

0.010

1.5

$(0.5,4.56)$

0.38

1.36

$(0.68,2.71)$

20 (11.1)

$2(1.1)$

2.12

$(0.19,23.62)$

0.40

0.058 2.97)

0.35

0.92

$31(17.2)$

0.54

$(0.30,0.82)$

$1.24(0.51, \quad 0.64$

$\begin{array}{lll}0.50 & 0.006 & 0.8 \\ (0.30,0.82) & & (0.43 \\ & & 1.49)\end{array}$

0.48

1.49)

Comorbidity

\begin{tabular}{|c|c|c|c|}
\hline HT & $70(36.5)$ & 77 (42.5) & $\begin{array}{l}1.29 \\
(0.85,1.96)\end{array}$ \\
\hline
\end{tabular}

DM

$63(32.8)$

$82(45.3)$

1.70

$(1.11,2.58)$

0.014

1.15

0.63

(0.65,

2.02)

CKD

$4(2.1)$

$39(21.5)$

12.91

$(4.51,36.96)$

$<.001$

9.47

(3.1,

28.91)

tValue in cell is mean (sd) instead of $n(\%)$

ҒAll these parameters came from the first day of ICU admission

BMI: body mass index, DM: diabetes mellitus, CAD: coronary artery disease, CVD: cerebrovascular disease, APACHE II: acute physiologic and chronic health evaluation II, SOFA: sequential organ failure assessment

NA: not included in the multivariable model even if $P<0.20$ because it didn't have enough data 


\begin{tabular}{|c|c|c|c|c|c|c|}
\hline \multirow[t]{2}{*}{ Characteristics } & \multicolumn{6}{|c|}{ Severity of AKI, $n(\%)$} \\
\hline & $\begin{array}{l}\text { Non-severe } \\
(\mathrm{N}=192)\end{array}$ & $\begin{array}{l}\text { Severe } \\
(N=181)\end{array}$ & $\begin{array}{l}\text { Unadjusted } \\
\text { OR }(95 \% \mathrm{Cl})\end{array}$ & $\begin{array}{l}\mathrm{P} \text { - } \\
\text { value }\end{array}$ & $\begin{array}{l}\text { Adjusted } \\
\text { OR (95\% } \\
\text { Cl) }\end{array}$ & $\begin{array}{l}\text { P- } \\
\text { value }\end{array}$ \\
\hline Cerebrovascular & $8(4.2)$ & $3(1.7)$ & $\begin{array}{l}0.39 \\
(0.10,1.48)\end{array}$ & 0.17 & & \\
\hline Malignancy & $6(3.1)$ & $12(6.6)$ & $\begin{array}{l}2.20 \\
(0.81,5.99)\end{array}$ & 0.12 & $\begin{array}{l}3.43 \\
(1.11 \\
10.57)\end{array}$ & 0.032 \\
\hline CAD & $10(5.2)$ & $9(5.0)$ & $\begin{array}{l}0.95 \\
(0.38,2.40)\end{array}$ & 0.92 & & \\
\hline APACHE-II score ${ }^{1}$ & $14.8(6.9)$ & $\begin{array}{l}18.3 \\
(7.3)\end{array}$ & $\begin{array}{l}1.07 \\
(1.04,1.10)\end{array}$ & $\begin{array}{l}<.001 \\
0.00\end{array}$ & $\begin{array}{l}1.07 \\
(1.01 \\
1.13)^{\prime}\end{array}$ & 0.018 \\
\hline Non-renal SOFA score ${ }^{1}$ & $4.6(2.4)$ & $5.5(2.6)$ & $\begin{array}{l}1.14 \\
(1.05,1.24)\end{array}$ & 0.002 & $\begin{array}{l}0.92 \\
(0.78 \\
1.08)\end{array}$ & 0.29 \\
\hline Vasopressors & $5(2.6)$ & $36(19.9)$ & $\begin{array}{l}9.29 \\
(3.55,24.26)\end{array}$ & $\begin{array}{l}<.001 \\
0.00\end{array}$ & $\begin{array}{l}5.41 \\
(1.8, \\
16.29)\end{array}$ & 0.003 \\
\hline Mechanical ventilation & $\begin{array}{l}83 \\
(43.2)\end{array}$ & $\begin{array}{l}102 \\
(56.4)\end{array}$ & $\begin{array}{l}1.70 \\
(1.13,2.55)\end{array}$ & 0.012 & $\begin{array}{l}1.31 \\
(0.69 \\
2.49)\end{array}$ & 0.41 \\
\hline
\end{tabular}

tValue in cell is mean (sd) instead of $n(\%)$

¥All these parameters came from the first day of ICU admission

BMI: body mass index, DM: diabetes mellitus, CAD: coronary artery disease, CVD: cerebrovascular disease, APACHE II: acute physiologic and chronic health evaluation II, SOFA: sequential organ failure assessment

NA: not included in the multivariable model even if $P<0.20$ because it didn't have enough data

Kaplan-Meier analysis were performed for survival analysis. It was tabulated for the duration of 60 days in hospital, and 28 days in ICU. In Fig. 3(a), the curve estimates overall survival from AKI on the basis of AKI staging in the hospital. Higher AKI stages associated with a significant increase in overall hospital mortality. Figure 3(b) shows that AKI patients have higher hospital mortality than non-AKI patients.

Median survival of hospital mortality for AKI patients is laid between 10 to 15 days and median survival for non-AKI patients laid in 30 days ( $p$ value $<0.001$ ). Kaplan-Meier curve for AKI patients in ICU is steeper than the curve for non-AKI patients, this means AKI patients have higher ICU mortality compared to nonAKI patients. Median survival for AKI patients laid below 7 days, while non-AKI patients survival rate is longer and laid between 14 to 21 days $(p<0.001)$ 


\section{Discussion}

Multiple studies have proven the detrimental impact of AKI on ICU patients, unfortunately their etiology and mechanism remain unclear. In ICU, a variety of conditions related to their reasons of admission such as infection, trauma, and other problems could prompt the induction of AKI or worsen any pre-existing condition of AKI. ${ }^{(1)}$ Therefore, this stressed out the important to study epidemiology of each countries, especially in the countries, like Indonesia, where resources were limited and might have different risk factors for the AKI development. AKI has been reported to occur in $20-50 \%$ of patients in ICUs around the world. ${ }^{\left({ }^{8}\right)}$ In Indonesia, at Central Army Hospital of Gatot Soebroto, almost half of ICU patients, $43 \%$ suffered from AKI. Thus, indicating that AKI is also a common problem in Indonesian ICU (Fig. 1). This high incidence of AKI may reflect the problem of public health issues and socioeconomic factors affect the epidemiology of AKI in low resource settings. ${ }^{(9)}$

Among 373 patients in ICU suffered from AKI, 181 patients (48.5\%) belong to stage III of the KDIGO criteria for AKI. Early diagnosis for AKI in ICU patients proved to be challenging, no wonder the number of patients with severe AKI in our center is high and might require extensive studies. Contrary to the results of most published studies, our center has higher proportion of AKI stage III compare to AKI stage I or II (Fig. 1). Recently, a published study in Australia reported that $37.1 \%$ patients on ICU who developed AKI, categorized as follows: AKI stage I 18.1\%; stage II 10.1\%; and stage III $8.9 \% .{ }^{(10)}$ Meanwhile, our data correspond to the data from less developed area. Recently, Srisawat et al reported the data from Thai ICU and showed the incidence of AKI stage $3(28.9 \%)$ was the most common followed by stage $2(16.4 \%)$ and stage 1 (7.5\%). ${ }^{111)}$ The investigators showed that most of AKI patients have reached AKI stage 3 at the time of ICU admission and might reflect the delayed ICU admission and delayed AKI recognition as the main explanation.

In our center, based on multivariate analysis using logistic regression, the significant factors contribute toward the severity of AKI were male, patients with CKD and malignancy, higher APACHE II score, and vasopressor usage (Table 4).

The mean of patients age with AKI in our center is 58 years old ( \pm 15 years old), and one published study in Malaysia which showed similar result of AKI severity, with more proportion of AKI Stage $3(56 \%)$ compare to AKI stage $1(18 \%)$ and AKI stage $2(25 \%)$, has similar mean of AKI patients' age with our center, 53 years old ( \pm 16 years old). ${ }^{(12)}$ But, there is no explanation on the association between age and AKI severity. Age might contribute as a risk factor of AKI occurrence in different races and countries. The causes not only because the kidney undergoes age dependent structural and functional alterations over time but also because of the comorbidities that accumulate with age. ${ }^{(13)}$ One experimental study using rats showed that aged rats exhibited reduced antioxidant potential and increased oxidative stress after ischemia-reperfusion, compare to young rats. ${ }^{(14)}$ This study showed that the total plasma antioxidant potential (AOP) of aged rats was lower than that of young rats regardless of whether they underwent ischemia-reperfusion. In addition, renal tissue 8-OHdG levels, which contributes to the destruction of 
kidney were increased in aged rats after reperfusion injury. Elderly patients have an increased risk for nonrecovery of renal function after acute ischemia and a heightened susceptibility to AKI. ${ }^{(15)}$

The two most comorbidities of AKI in our study was hypertension and diabetes mellitus, with the number of patients admitted with those conditions were 147 and 145 patients respectively. This study is comparable to previous study in 2013 showed that diabetes was associated with a 2.8 fold increased risk of developing AKI. ${ }^{(16)}$ The mechanism by which diabetes increases the severity of AKI has not yet been well established, but a great deal of research supports the connection between obesity, inflammation, and

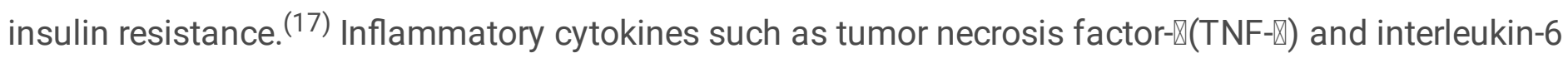
(IL-6) are produced by adipocytes and have been shown to cause insulin resistance. ${ }^{(18)}$

History of hypertension in patients also contributed to the increased risk of AKI incidences (OR, 1.13; $95 \%$ $\mathrm{Cl}, 1.02-1.05)$. Hypertension is commonly found in patients with AKI and vice versa due to several mechanism with inter-related complications, such as balance disorders of vascular active substances, renin-angiotensin system activation, changes in inflammatory factors, and increases in active oxygen species. ${ }^{(19)}$ Inflammation causes changes in endothelial function and further increasing the arterial stiffness, oxidative stress and increased circulating angiotensin II levels caused by inflammation will also reduce the availability of nitric oxide (NO) and worsen the vascular damage. Thus, the combination of hypertension, increased angiotensin II levels and oxidative stress initiates events will also lead to the damage of the renal system. ${ }^{(20)}$

In this study, 9.47 times more likely to have CKD as their comorbidities. In recent years, studies in different regions have found that CKD is a strong risk factor for the development of AKI, mainly in septic patients. Currently, CKD is found in $30 \%$ of patients who develop AKI in the intensive care unit (ICU). ${ }^{(21)}$ It is noteworthy that CKD was the variable with the highest percentage of association, which makes it a strong predictor for the development of AKI in critically ill patients.

This study confirmed that almost a half population (49.6\%) of patients with AKI needed mechanical ventilation, while less than a fifth (17.3\%) among non-AKI patients required the use of mechanical ventilation. Compared with ventilated non-AKI patients, ventilated AKI patients had a higher APACHE and three days SOFA score. This study result might support current view that AKI in ICU is a prominent risk factor contributes to the worsening of patients' health conditions, more specifically in low-risk AKI-RRT patients. ${ }^{(22)}$ Based on the study conducted by Vieira, et al shows that renal dysfunction has serious consequence in the duration of mechanical ventilation and weaning from mechanical ventilation. The median duration of mechanical ventilation use in AKI patients was 3 days longer than non-AKI patients (10 vs 7 days). ${ }^{(23)}$ The underlying mechanism that may contribute to the use of mechanical ventilation in AKI patients because patients experienced severe acute respiratory insufficiency, which will increase the intrathoracic pressure to reach acceptable gas exchange to compensate these changes. This will eventually result in renal dysfunction such as renal tubular apoptosis. ${ }^{(22)}$ 
There are 92 patients (24.6\%) AKI patients required RRT(AKI-RRT), this result might validate the importance of RRT in ICU settings, despite certain challenges such as availability of modalities and understaffing of nephrologist. ${ }^{(24)}$ It is important to remember that AKI is a case with a staggering amount of mortality rates, especially for critically ill patients in ICU setting. ${ }^{(25)}$

At our center, like most hospitals in developing country, IHD is the most commonly used method (66 procedures, $71.7 \%$ ). On the other hand, a study using online questionnaire responded by members of European Society of Intensive Care Medicine from 50 countries, showed that half of the intensivists, preferred the use of CRRT compare to IHD. The reasons for preferring CRRT were the perception of better hemodynamic stability, better therapeutic effect resulting from cytokine removal and easier fluid balance control. (26)

A cohort study done by Mandelbaum, et al. to measure the outcome of critically ill patients with AKI shown that the rate of hospital mortality and ICU mortality are both worse in patients with AKI at any given stage compared to in-hospital mortality rate in non-AKI patients, shown as follow: rate of mortality in non-AKI patients were $6.25 \%$, AKI stage I $13.87 \%$, AKI stage II $16.42 \%$, and AKI stage III $33.76 \%$. The ICU mortality rate is also higher in AKI patients as follow non-AKI 4.54\%, AKI stage I 10.06\%, AKI stage II 13.15\%, and AKI stage III 30.48\%.(27) A significant survival differences is shown by Kaplan-Meier survival curves according to the presence of AKI, where the curve for AKI patients survival is steeper compare to non-AKI patients. This represents worse survival rate in patients with AKI compare to non-AKI. ${ }^{(28)}$ With previous published studies clearly emphasized the worse outcome in AKI patients compare to non-AKI patients, we are certain that it is important to prevent AKI from happening or to manage AKI at earlier stage. This will be beneficial to decrease the healthcare burden and bring betterment towards patients' overall survival rate.

We believe that identification the risk factor of AKI will provide the opportunity to develop the predictability score for AKI prevention and finally improve AKI outcome. Another key strength was the availability of data to permit the detailed analysis of risk factors of AKI between mild (AKI stage 1/2) and severe AKI (AKI stage 3), something that has received little attention. Another strength was that our AKI criteria were from KDIGO which employs both the information from creatinine and urine output data. This research will be a reference research for other studies of AKI patients in ICU in other hospitals, especially in Indonesia. However, this reference will improve the completeness of epidemiological data and risk factors for AKI patients in Indonesia.

Our study did have limitation. We collected data only in ICU patients in Gatot Soebroto Hospital. So our patient sample may not truly represent the incidence of AKI in all hospitalized ICU patients in all over Indonesia.

\section{Conclusion}


In Indonesia, like other developing countries, many ICU patients are at risk of developing AKI. The incidence of $\mathrm{AKI}$ in our center alone exceeds almost half of the patients (43\%) with $48.5 \%$ belong to stage III.

\section{Declarations}

\section{Ethics approval and consent to participate}

The study protocol was reviewed by the institutional review boards (IRB No. B/2212/VIII/2019) and the need for informed consent was waived.

\section{Consent for publication}

Not applicable

\section{Availability of data and materials}

The datasets used during the current study are available from the corresponding author on reasonable request.

\section{Authors' contributions}

Conceived and design the study: J, NS. Enrolled the patients and conducted the study: J, MH, VA, AJ, LH, VK, NS. Analyzed the data: J, NS. Wrote the paper: J, NS. All authors read and approved the final manuscript.

\section{Competing interests}

Authors declare that they have no competing interests.

\section{Funding}

Financial support for the study was provided by the International Society of Nephrology (ISN), The Kidney Foundation of Thailand, and The Medical Association of Thailand. 


\section{Authors' details}

${ }^{1}$ Division of Nephrology, Departement of Internal Medicine, Gatot Soebroto Indonesia Central Army Hospital, Jakarta, Indonesia

${ }^{2}$ Departement of Anesthesiology and Reanimation, Gatot Soebroto Indonesia Central Army Hospital, Jakarta, Indonesia

${ }^{3}$ Division of Nephrology, Department of Medicine, Chulalongkorn University, Bangkok, Thailand

${ }^{4}$ Critical Care Nephrology Research Unit, Faculty of Medicine, Chulalongkorn University, Bangkok, Thailand

${ }^{5}$ Academic of Science, Royal Society of Thailand, Bangkok, Thailand

${ }^{6}$ Tropical Medicine Cluster, Chulalongkorn University, Bangkok, Thailand.

\section{Acknowledgement}

We wish to thank the database of ICU in Gatot Soebroto Central Army Indonesia Hospital for access to the data used in this study. The authors would like to acknowledge the team from the Excellence Center for Critical Care Nephrology, King Chulalongkorn Memorial Hospital, Thailand for their assistances in data collection,the programmers from electronic medical record-LIFE (EMR-LIFE) company for the excellent web-based medical records support.

\section{References}

1. Weening J. Advancing nephrology around the globe: an invitation to contribute. Journal of the American Society of Nephrology. 2004;15(10):2761-2.

2. Uchino S, Bellomo R, Morimatsu H, Morgera S, Schetz M, Tan I, et al. Continuous renal replacement therapy: a worldwide practice survey. 2007;33(9):1563-70.

3. Uchino S, Kellum JA, Bellomo R, Doig GS, Morimatsu H, Morgera S, et al. Acute renal failure in critically ill patients: a multinational, multicenter study. JAMA. 2005;294(7):813-8.

4. Dennen P, Douglas IS, Anderson RJCcm. Acute kidney injury in the intensive care unit: an update and primer for the intensivist. 2010;38(1):261-75.

5. Thakar CV, Christianson A, Freyberg R, Almenoff P, Render MLJCcm. Incidence and outcomes of acute kidney injury in intensive care units: a Veterans Administration study. 2009;37(9):2552-8.

6. Mehta RL, Kellum JA, Shah SV, Molitoris BA, Ronco C, Warnock DG, et al. Acute Kidney Injury Network: report of an initiative to improve outcomes in acute kidney injury. 2007;11(2):R31. 
7. Suh SH, Kim CS, Choi JS, Bae EH, Ma SK, Kim SWJYmj. Acute kidney injury in patients with sepsis and septic shock: risk factors and clinical outcomes. 2013;54(4):965-72.

8. Srisawat N, Kellum JA. Acute kidney injury: definition, epidemiology, and outcome. Current opinion in critical care. 2011;17(6):548-55.

9. Mehta RL, Cerdá J, Burdmann EA, Tonelli M, García-García G, Jha V, et al. International Society of Nephrology's 0by25 initiative for acute kidney injury (zero preventable deaths by 2025): a human rights case for nephrology. The Lancet. 2015;385(9987):2616-43.

10. Bagshaw SM, George C, Bellomo R. A comparison of the RIFLE and AKIN criteria for acute kidney injury in critically ill patients. Nephrology Dialysis Transplantation. 2008;23(5):1569-74.

11. Srisawat N, Kulvichit W, Mahamitra N, Hurst C, Praditpornsilpa K, Lumlertgul N, et al. The epidemiology and characteristics of acute kidney injury in the Southeast Asia intensive care unit: a prospective multicentre study. Nephrology Dialysis Transplantation. 2019; doi:10.1093/ndt/gfz087.

12. Ralib AM, Nor MBM. Acute kidney injury in a Malaysian intensive care unit: Assessment of incidence, risk factors, and outcome. Journal of critical care. 2015;30(3):636-42.

13. Hsu C-y, Chertow GM, McCulloch CE, Fan D, Ordoñez JD, Go ASJCJotASoN. Nonrecovery of kidney function and death after acute on chronic renal failure. 2009;4(5):891-8.

14. Kusaka J, Koga H, Hagiwara S, Hasegawa A, Kudo K, Noguchi T. Age-dependent responses to renal ischemia-reperfusion injury. Journal of Surgical Research. 2012;172(1):153-8.

15. Himmelfarb J, editor Acute kidney injury in the elderly: problems and prospects. Seminars in nephrology. Elsevier. 2009; doi: 10.1016/j.semnephrol.2009.07.008.

16. Finlay S, Bray B, Lewington A, Hunter-Rowe C, Banerjee A, Atkinson J, et al. Identification of risk factors associated with acute kidney injury in patients admitted to acute medical units. 2013;13(3):233-8.

17. Kim JK. Fat uses a TOLL-road to connect inflammation and diabetes. Cell metabolism. 2006;4(6):417-9.

18. Lang CH, Dobrescu C, Bagby GJJE. Tumor necrosis factor impairs insulin action on peripheral glucose disposal and hepatic glucose output. 1992;130(1):43-52.

19. Wang Z, Wu Y, Zhao L, Li Y, Yang J, Zhou BJHr. Trends in prevalence, awareness, treatment and control of hypertension in the middle-aged population of China, 1992-1998. 2004;27(10):703-9.

20. Pietri P, Vlachopoulos C, Tousoulis DJCmc. Inflammation and arterial hypertension: from pathophysiological links to risk prediction. 2015;22(23):2754-61.

21. Tejera D, Varela F, Acosta D, Figueroa S, Benencio S, Verdaguer $C$, et al. Epidemiology of acute kidney injury and chronic kidney disease in the intensive care unit. 2017;29(4):444-52.

22. Skarupskienè I, Adukauskienè D, Kuzminskienė J, Rimkutè L, Balčiuvienè V, Žiginskienè E, et al. Mortality prediction in patients with acute kidney injury requiring renal replacement therapy after cardiac surgery. 2017;53(4):217-23. 
23. Vieira Jr JM, Castro I, Curvello-Neto A, Demarzo S, Caruso P, Pastore Jr L, et al. Effect of acute kidney injury on weaning from mechanical ventilation in critically ill patients. 2007;35(1):184-91.

24. Ronco C, Ricci Z, De Backer D, Kellum JA, Taccone FS, Joannidis M, et al. Renal replacement therapy in acute kidney injury: controversy and consensus. Critical care. 2015;19(1):146.

25. Ehieli, Bronsteyn. Intensity of Renal Support in Critically III Patients with Acute Kidney Injury. 50 Studies Every Intensivist Should Know. 2018:221.

26. Legrand M, Darmon M, Joannidis M, Payen D. Management of renal replacement therapy in ICU patients: an international survey. Intensive care medicine. 2013;39(1):101-8.

27. Mandelbaum T, Scott DJ, Lee J, Mark RG, Malhotra A, Waikar SS, et al. Outcome of critically ill patients with acute kidney injury using the AKIN criteria. 2011;39(12):2659.

28. Wijewickrama ES, Ratnayake GM, Wikramaratne C, Sheriff R, Rajapakse SJBrn. Incidences and clinical outcomes of acute kidney injury in ICU: a prospective observational study in Sri Lanka. 2014;7(1):305.

\section{Figures}

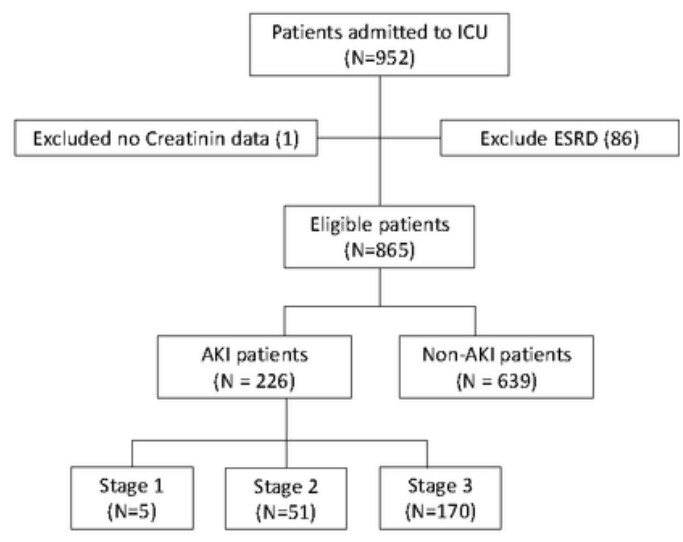

Figure 1. Study flow chart

\section{Figure 1}

Study flow chart ICU, Intensive Care Unit; ESRD, End Stage Renal Disease; AKI, Acute Kidney Injury 


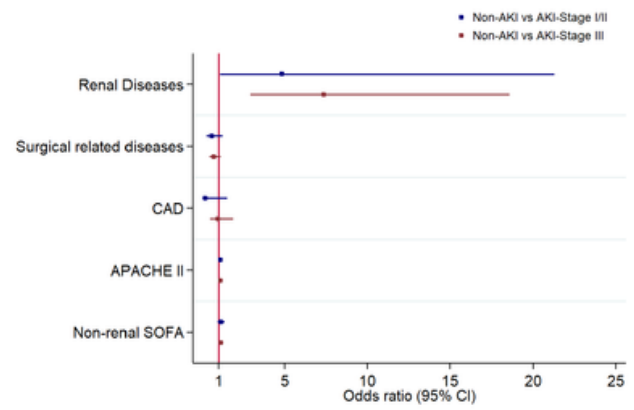

Figure 2. Forest plot of risk factors of AKI, no AKI vs stage 1 or stage 2, no AKI vs AKI stage 3

\section{Figure 2}

Forest plot of risk factors of AKI, No-AKI vs stage-1/stage-2, No-AKI vs AKI stage-3 CAD, Cardiovascular Disease; APACHE II, Acute Physiologic and Chronic Health Evaluation; SOFA, Sequential Organ Failure Assessment

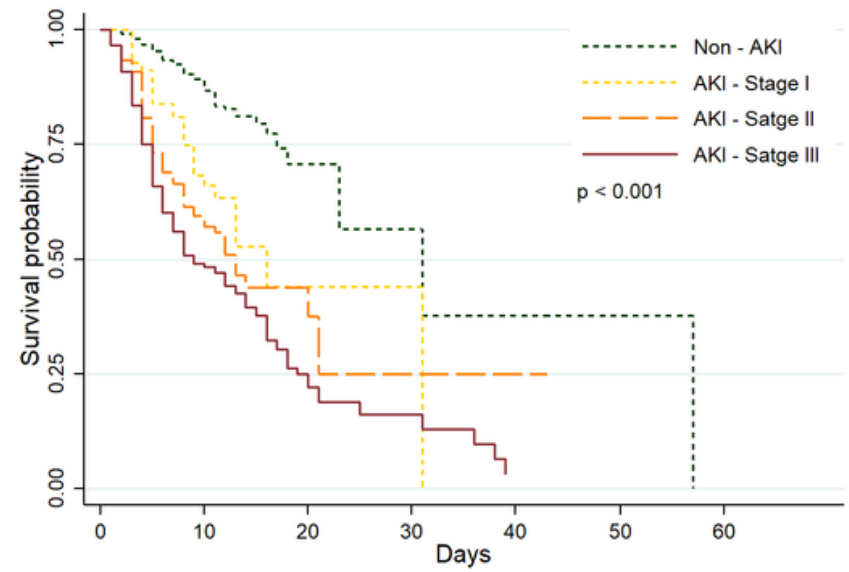

Number at risk

Non - AKI 490

$\begin{array}{rc}\text { Non - AKI } & 490 \\ \text { AKI - Stage I } & 69\end{array}$

AKI - Stage II 120

AKI - Stage III 176

$\begin{array}{cccccc}274 & 12 & 3 & 2 & 1 & 0 \\ 31 & 1 & 1 & 0 & 0 & 0 \\ 53 & 7 & 2 & 1 & 0 & 0 \\ 78 & 18 & 5 & 0 & 0 & 0\end{array}$

Figure 3. Kaplan-Meier survival curves for each AKI stage on hospital mortality, $\mathrm{N}=855$ (excluded 10 event time missing).

\section{Figure 3}

Kaplan-Meier survival curves for each AKI stage on hospital mortality 